\title{
UMA EXPERIÊNCIA ETNOFOTOGRÁFICA NUM PRESÍDIO FEMININO
}

\author{
Micheline Ramos de Oliveira ${ }^{1}$
}

Atentando para o fato do não esquecimento da 'grafia da luz' que preside a experiência noética da interpretação da cultura do outro, proponho o debate sobre as funções fabulatórias nos jogos de memória pelo exercício de uma etnografia da duração $^{2}$, evidenciando a produção de imagens fotográficas em um campo altamente restritivo à produção de imagens: um presídio feminino ${ }^{3}$.

Para tanto, tento revelar, por meio da descrição das situações e dos momentos em que o ato de produzir as imagens se deu, aliado às minhas escolhas sobre quais imagens seriam aqui expostas, "as condições sob as quais o próprio pensamento do antropólogo constrói, reproduz e disponibiliza para o mundo acadêmico, ou não" o material etnográfico (Eckert; Rocha, 2004: 8).

Remetendo-me rapidamente ao inicio de minhas negociações em campo a respeito da produção de imagens em um espaço vigiado, controlado, escondido, como o prisional, relembro uma reunião realizada com o diretor do presídio, falando-lhe da importância das imagens como narrativas para minha pesquisa e reafirmando meu compromisso ético com as "presidiárias". Naquele momento, obtive a permissão para fazer uso de uma máquina fotográfica em minhas visitas na referida instituição.

Passada essa etapa crucial para obter a permissão necessária para adentrar o presídio feminino, conversei com as mulheres que se encontravam em situação de cárcere que, por sua vez, não se opuseram à produção de imagens com o uso da máquina fotográfica, desde que suas identidades fossem preservadas ${ }^{4}$ e que pudessem receber, em troca, algumas fotografias, principalmente para enviarem aos seus

\footnotetext{
${ }^{1}$ Universidade Federal de Santa Catarina, Brasil.

${ }^{2}$ Aqui me inspiro em Gaston Bachelard. A dialética da Duração, 1994.

3 Esse artigo é uma compilação de um capítulo de minha tese de doutorado intitulada "No limiar da Memória: estudo antropológico sobre mulheres e violências na metrópole contemporânea" defendida em 2009, sob a orientação de Ana Luíza Carvalho da Rocha, no PPGAS/UFSC. Além da gratidão para com minha orientadora, agradeço a imensa colaboração de Gilberto Velho; Cornelia Eckert; Alícia Castells e Sônia Maluf, membros de minha banca de defesa de tese, cujas valiosas idéias foram trabalhadas aqui. Fragmentos desse artigo foram apresentados na $28^{\mathrm{a}}$ Reunião Brasileira de Antropologia, realizada entre os dias 02 e 05 de julho de 2012 em São Paulo, SP, Brasil.

${ }^{4}$ Sobre a questão da ética e o uso da imagem na antropologia social ver principalmente Eckert e Rocha (2004). Nesse artigo, as autoras fazem um apanhado em torno do estado da arte da discussão sobre ética e imagem na antropologia brasileira; dos problemas advindos da experiência de pesquisadores com o uso da imagem e, por último, tecem reflexões sobre a ética e a imagem.
} 
companheiros, às suas companheiras e seus familiares ${ }^{5}$.

Vale lembrar que, geralmente, a produção de imagens sobre e dessas pessoas se dá em contextos em que aparecem em jornais e revistas apenas em reportagens sobre crimes, contravenções e assassinatos. Assim, creio que o tratamento do tema das técnicas e dos procedimentos de pesquisa de campo, a partir da imagem do outro, se torna importante em uma reflexão engajada em problematizar " [...] a consciência de si e do outro ao longo e após o trabalho de campo" (Eckert; Rocha, 2004: 8). Nesse sentido, vejamos esse trecho de meu diário de campo, escrito logo depois da confecção das imagens fotográficas que serão expostas a seguir:

Hoje, durante as imagens fotográficas que fiz, tentei deixar as meninas o mais à vontade possível [...] e, como estava utilizando máquina digital, conforme havia combinado, deixei que elas selecionassem as imagens que poderiam vir a compor minha tese. Fiquei preocupada com os ângulos, o cenário e as cenas que escolhi para fotografar. Não que não poderiam dar conta do "real" já que isso está fora de cogitação ${ }^{6}$, mas que isso não contribuísse para alguns estigmas que frequentemente estão relacionados às presidiárias [...] principalmente com a exposição de seus corpos femininos [...].

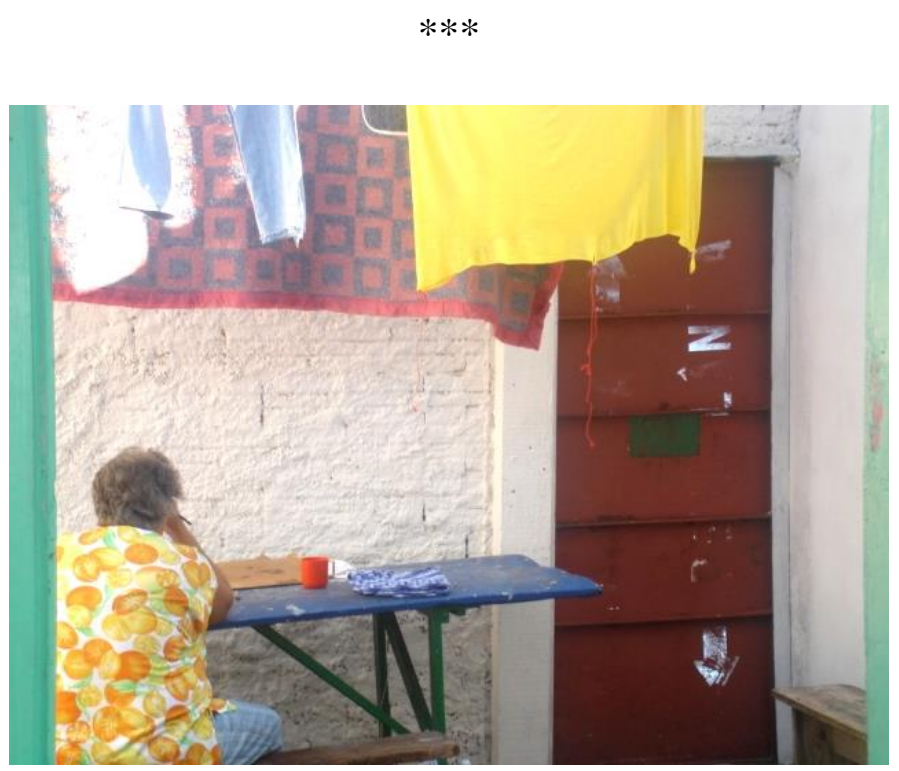

1. Cotidiano no presídio feminino: "Hora de Estudo I" - Presídio Feminino de Rio do Sul/SC. Março de 2007. Autoria: Micheline Ramos de Oliveira.

\footnotetext{
${ }^{5}$ As imagens fotográficas contidas nesse artigo foram confeccionadas em 2007 no presídio Feminino de Rio do Sul/Santa Catarina. Discutido juntamente com minhas interlocutoras, alguns artifícios foram utilizados para a preservação de suas identidades, como o uso de tarjas em suas faces (imagens as quais descartei para essa empresa por chegar à conclusão que poderiam não funcionar a serviço da preservação de identidade) e imagens fotográficas que não focalizasse seus rostos, como poderá ser visto adiante. Já as fotografias entregues as interlocutoras foram realizadas sem restrições.

6 " $\mathrm{Em}$ antropologia visual, investir no tratamento meramente representacional da imagem técnica seria lhe conceder o papel de simulação do mundo das coisas, sem aprender as operações cognitivas que têm por objeto a imagem, operações que constituem transformações e não apenas a reprodução dos estados das coisas" (Rocha, 2004: 5).
} 


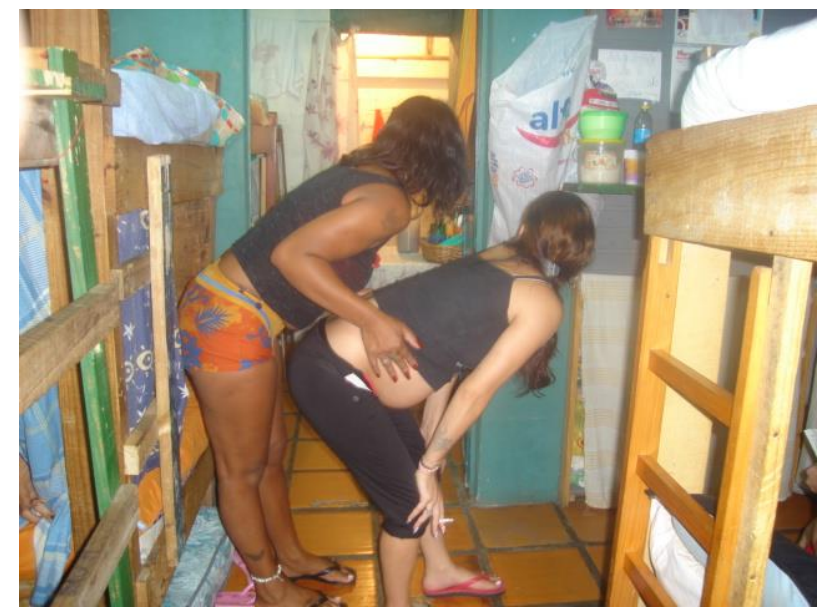

2. Cotidiano no presídio feminino: "Dançando Funk" - Presídio Feminino de Rio do Sul/SC. Março de 2007. Autoria: Micheline Ramos de Oliveira.

As imagens pela antropóloga e por elas selecionadas dizem respeito a aspectos do cotidiano interceptado pela presença incomum da antropóloga, seja um momento de recolhimento em um canto do presídio, seja junto às colegas de cela em que brincam, fazem pose, se insinuam para a câmera de tal forma que a câmera capte o gesto de seus corpos, mas não o rosto que as delataria. Momentos de risos, até mesmo de "bagunça", em que, por breves instantes, rápidos o suficiente em que o clic da máquina fotográfica capta as imagens, elas parecem esquecer os instantes, as horas, às vezes, os anos de cárcere. Há nestes breves instantes o exercício, por um lado, da antropóloga e, por outro, das presidiárias, que diz respeito a uma consciência de si e do outro ao longo e que poderá reverberar após o trabalho de campo.

A escolha de narrar o cotidiano dentro do presídio está relacionada ao tema da dialogicidade, da alteridade e da mesmidade, da antropologia compartilhada rouchiana ${ }^{7}$, onde as decisões da construção da imagem do outro são efetuadas segundo a perspectiva do nativo, no sentido de haver a restauração da "fala" do outro.

Trata-se de o nativo se ver a partir da "fala" narrada pela imagem que ele, no caso, as encarceradas, elaboram e re-elaboram. É o espaço da construção de uma experiência de vida que não é mais aquele instante que se esvai tal qual o clic que capta uma imagem.

\footnotetext{
${ }^{7}$ Ver Jean Rouch. Por La Photographie/Ed.Ciro BRUNI. Sammeron, Germs, 1983, p. 371-375 (Actes Du 1 er Colloque international pour La photographie) - Université Paris- VIII, 1982.
} 
Aqui o tema da imagem fotográfica como duplo do real é um elemento importante dessa análise, isso porque, estamos tratando da mesmidade de meus interlocutores (identidade-idem) em relação à antropóloga como alteridade deles (um primeiro patamar da identidade ipse). Nesse sentido, a fotografia desencadeia uma outra crise no plano narrativo da identidade. Qual seja a da ipseidade, visto que eles (interlocutores) não se sentem mais eles próprios, os mesmos, não mais em relação à antropóloga, mas em relação a si mesmos. A presença da antropóloga entre eles aponta para isso.

Neste aspecto, durante a confecção de algumas imagens, emergiu a fala de uma de minhas interlocutoras, que vai ao encontro dessa argumentação:

Acho legal as pessoas verem lá fora que não somos animais [...] que a gente ta presa mas é normal [...] faz coisas como as outras pessoas [...] não somos monstros, nem bichos [...] como muita gente pensa por aí [...]. Tem um monte de menina boa aí [...] fazem um monte de coisa legal [...]. Só não deram sorte na vida [...].

Uma fala que diz respeito a ponderações sobre uma normalidade de si, e um desejo de que o outro, ao ver as imagens selecionadas, consiga vê-lo não como um bicho, ou como um monstro, mas um si mesmo também semelhante a este outro. As imagens a seguir, das quais se refere esta "fala" dizem muito sobre o que a fala quer falar, que diz respeito a seres humanos normais, mas que não deram sorte na vida.

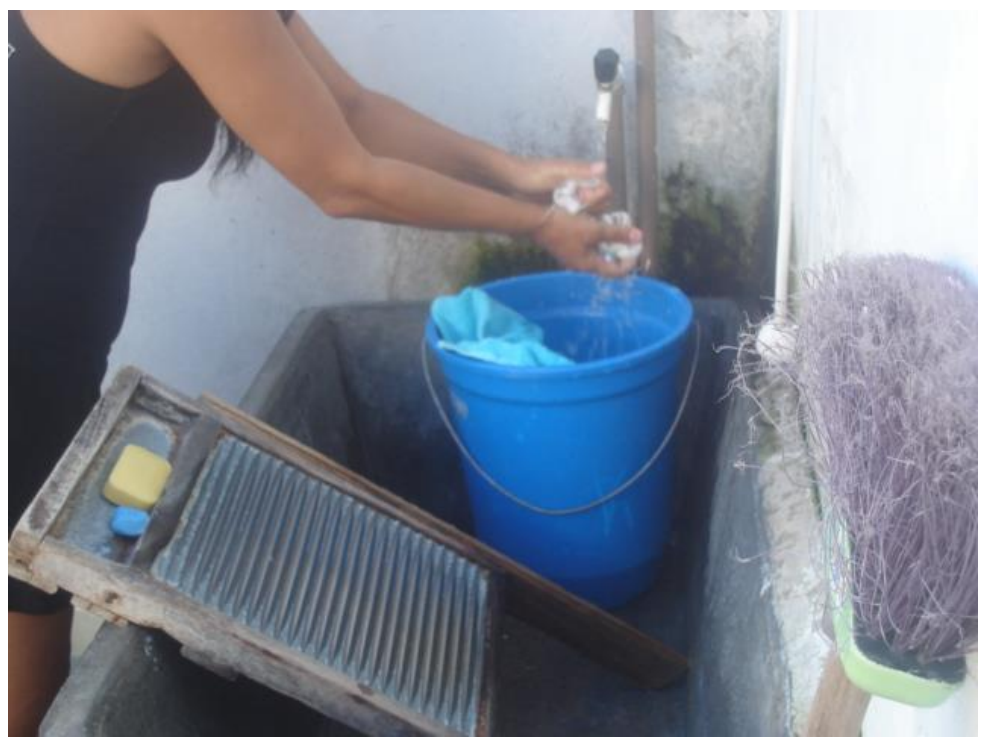

3. Cotidiano no presídio feminino: "Lavando Roupa" - Presídio Feminino de Rio do Sul/SC. Março de 2007. Autoria: Micheline Ramos de Oliveira. 


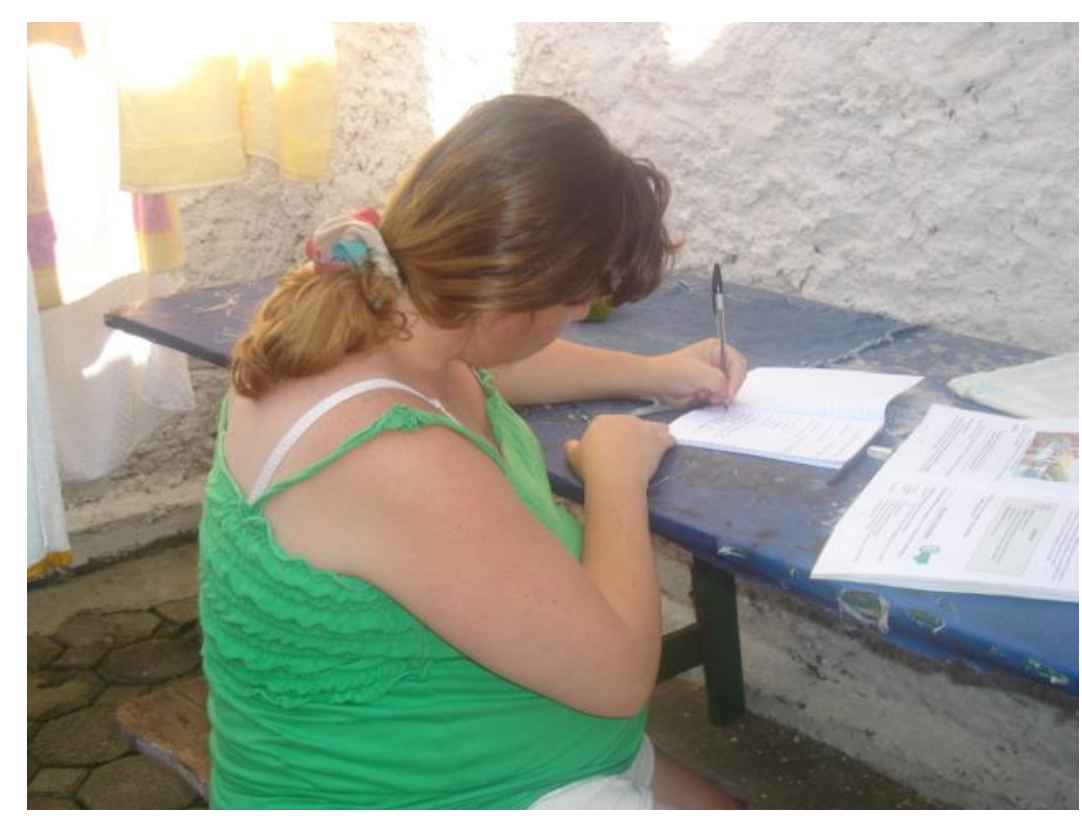

4. Cotidiano no presídio feminino: "Hora de estudo II" - Presídio Feminino de Rio do Sul/SC. Março de 2007. Autoria: Micheline Ramos de Oliveira.

Aqui devo advertir que o uso dessas imagens não foi feito na tentativa de "ler o destino" dessas mulheres "na face das coisas, o que significaria o tratamento da “identidade" de ser presidiária "a partir dos objetos da representação empírica" que captei com minha câmera fotográfica. A exposição dessas imagens converge para a tentativa de compreender que os estudos antropológicos, por meio do uso de imagens, exigem "uma conversão do antropólogo nas condições reflexiva e reversível nas quais se gesta seu próprio pensamento" (Eckert; Rocha, 2004: 8).

Nesse sentido, pensando sobre os recursos tecnológicos que conformam a linguagem empregada pela antropologia visual como uma expressão inegável, portanto, de uma poiésis (Rocha, 1995), ratifica-se aqui a positividade de assumirmos a ficção como constituinte de nosso metier. Ficção não como o antônimo de verdade, nem de realidade, ou como o sinônimo de mentira, mas como o reconhecimento da imagem fotográfica como processo e resultado de uma autoria, lugar onde a pretensa neutralidade cientificista não encontra eco, e em que a subjetividade e o olhar do autor estão fatalmente ligados à sua obra.

Aqui, para complexificar nossa discussão, é importante pontuar que a noção de autoria vinculada à constituição da imagem deve perpassar a reflexão de que "uma 
investigação a partir da imagem nos remete, hoje, à construção de nossas próprias imagens internas, isto é, às formas simbólicas através da qual o próprio conhecimento antropológico se expressa" (Eckert; Rocha, 2001: 7). Enfim, em que a interpretação paradoxalmente encoberta por um movimento que se dizia iluminista ${ }^{8}$ deixa as trevas e passa a ascender em nossas discussões. Estou me referindo ao tema da imagem não como duplo/cópia do real, mas como mimese, imitação da ação, do "estive lá" a partir do aqui e do agora da escrita (Ricoeur, 2001).

Nesse contexto, vale uma digressão: para Aristóteles, a imitação tem validade cognoscitiva porque a poiésis não representa as coisas realmente acontecidas, mas "as coisas possíveis, segundo a verossimilhança e a necessidade". A ficção anularia a "verdade", neste momento entendida como uma pretensa fidelidade à experiência, e a substituiria pela criação de ordem. Tal como é encerrada pela narração etnográfica em antropologia visual, para Aristóteles, a ficção consiste na "ordem", na "simetria" e em uma grandeza que se presta a ser abarcada pela visão em seu conjunto.

Dentre outros, os clássicos trabalhos, como os de Etienne Samain, Malinowski, Bateson e até mesmo Franz Boas são esclarecedores, já que, respeitando todas as peculiaridades, cada um desses antropólogos usou a imagem fotográfica para recriar o mundo nos quais os seus nativos viviam. Nestes termos, partindo da ideia de que uma “criação de ordem” está grudada ao ato do antropólogo em suas narrativas etnográficas, faz-se instigante arranjar "esteticamente a discordância dos instantes vividos que conformam uma existência humana numa lógica da concordância" (Rocha, 1995).

Aqui, vale a pena parar e retomar, no caso dessa discussão, as discordâncias de instantes aos quais quero fazer alusão me referindo aos arranjos que a escrita ou as imagens, especificamente, conseguem ordenar em termos do tempo da narrativa de um encontro etnográfico com a alteridade que os estudos de violência, gênero e cidade pretendem dar conta. Nesse sentido, vamos a mais uma sequência de imagens produzidas no cárcere em que, ao me debruçar sobre elas, o foco que emerge diz

\footnotetext{
${ }^{8}$ Rouanet (1998) problematizando o "olhar iluminista" vai buscar no diálogo com os enciclopedistas, que nas figuras, principalmente de Diderot e Voltaire, pautados numa perspectiva do indivíduo, problematizam o ideal da visibilidade e a incompetência do olhar como reduzidos, o primeiro à capacidade que o sujeito tem de ver tudo isso, se educado para deixar de lado o préjugé, e o segundo, como conseqüência do poder exercido sobre o sujeito por outras pessoas. Prosseguindo, o autor aponta que os enciclopedistas deram ênfase, principalmente ao "olhar que vê", deixando para Rousseau o papel de resgatar o "olhar que é visto". Aqui, a transparência e a reciprocidade legitimam aquilo que utopicamente viria a ser chamado de Contrato Social. Como os filósofos da ilustração, Rousseau cai em sua própria armadilha e o mundo da reciprocidade e da transparência cai por terra mesmo antes de florescer.
} 
respeito a questões corporais e de gênero. Inscrições que compõem suas memórias individuais e sociais, a partir de onde penso que a presença de motivos florais e de figuras do bestiário, circunscritos em seus corpos por meio de tatuagens, podem nos auxiliar a pensar sobre a forma como elas registram em seus próprios corpos suas falas acerca do mundo.

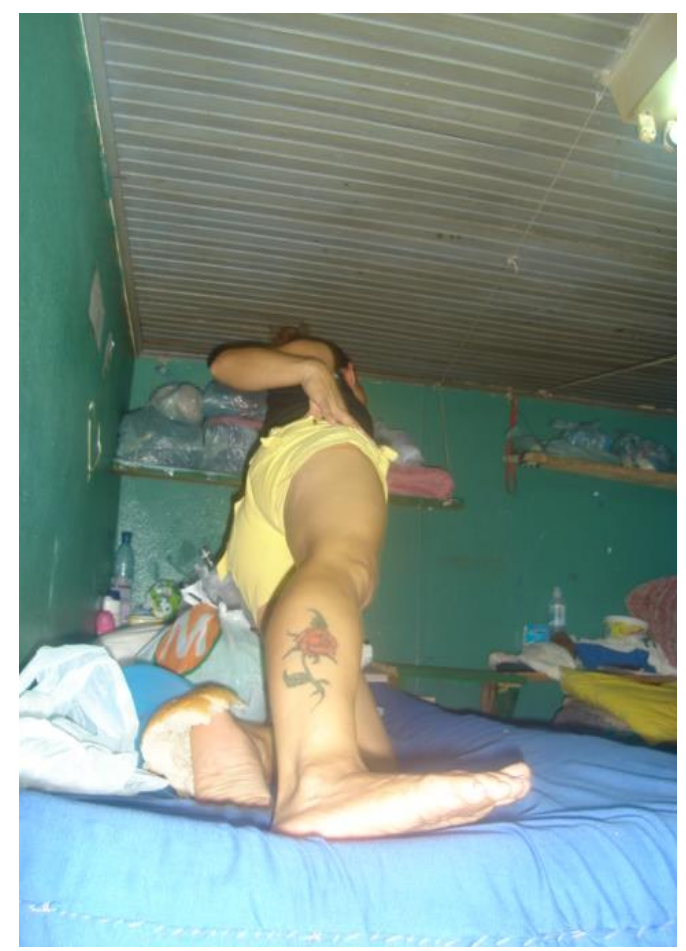

5. Cotidiano no presídio feminino: "Minha perna tatuada I" - Presídio Feminino de Rio do Sul/SC. Março de 2007. Autoria: Micheline Ramos de Oliveira. 


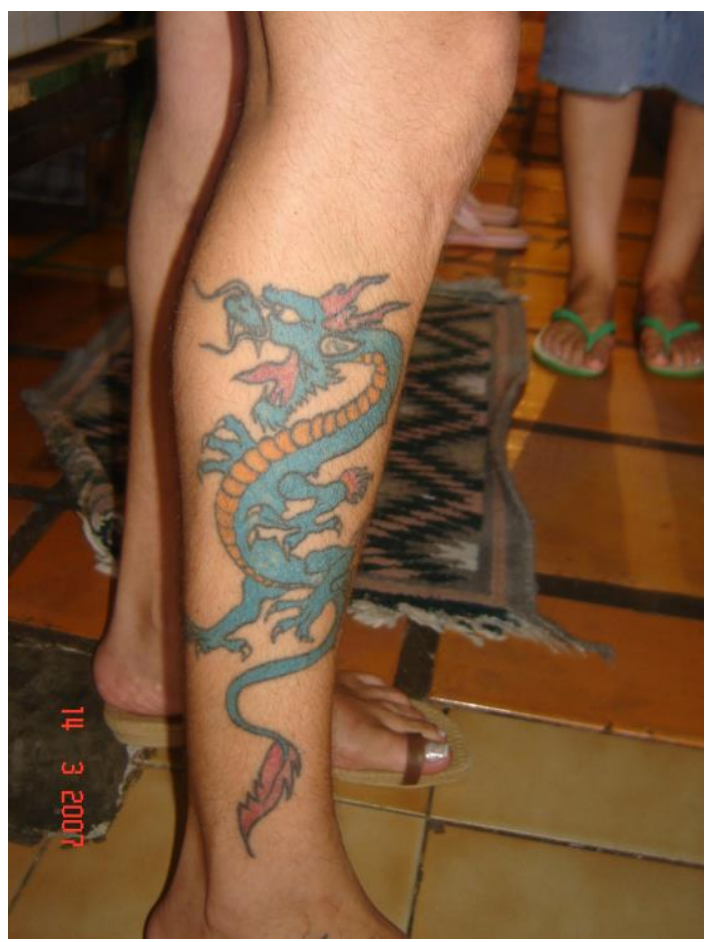

6. Cotidiano no presídio feminino: "Minha perna tatuada II" - Presídio Feminino de Rio do Sul/SC. Março de 2007. Autoria: Micheline Ramos de Oliveira.

Lembrando do pedido de minhas interlocutoras para que eu fizesse fotografias de suas tatuagens, o mais importante aqui é prestarmos atenção para as grafias ali circunscritas e o que minhas interlocutoras estão buscando "falar" comigo e com todos nós ${ }^{9}$ que estamos fora do cárcere. Isso, no sentido do tema da tatuagem ser resgatado em termos das inscrições que representam na rítmica da vida dessas mulheres, uma espécie de grafia de outra ordem, e também do registro do tempo e de suas memórias.

Penso que essa reflexão torna-se fundamental a partir do momento em que confabulo, mais uma vez, com Eckert e Rocha (2004: 12) que consideram "o uso da imagem na pesquisa antropológica um espaço privilegiado de reflexão em torno de visibilidade representacional das formas de alteridade cultural". Nesse sentido, o ato de fabricação da imagem por meio do uso da máquina digital (as possibilidades dadas pelo uso da máquina digital, de retorno imediato, da destruição imediata do que não serve, de se ver a imagem no monitor no momento da sua captação compartilhando-o com o

\footnotetext{
${ }^{9}$ Nesse sentido, vale a pena recorrer a Diógenes (2001: 193). Segundo a autora: "As inscrições nos corpos dos tatuados cumprem a sua função, de falar por imagens, seguindo o curso da vida; até que algum dia, a palavra, como meio de identificação, de contrato social, de reconhecimento público possa retomar um estatuto perdido".
} 
outro) parece possibilitar a revelação do lugar do etnógrafo diante do outro, contribuindo assim com as trocas $\mathrm{e}$ as relações intersubjetivas entre nativo $\mathrm{e}$ antropólogo, necessárias para o bom andamento da etnografia, principalmente num campo delicado como esse.

Em relação a essa questão, abstraio mais um fragmento de meu diário de campo de doutorado, seguido por uma imagem fotográfica:

Quando me dei conta, vi que o processo de fotografar minhas interlocutoras contribuiu para nossa aproximação [...]. Parece que a narrativa fotográfica fez com que elas vissem de forma mais imediata, por meio das imagens no monitor da câmera digital, o resultado de minha etnografia, o que as empolgou no sentido de quererem falar e exteriorizar o que estavam sentindo [...]. Isso ficou claro no pedido de uma de minhas interlocutoras para que eu fotografasse a falta de luz na cadeia, o que retrataria segundo suas palavras a falta de perspectiva de futuro que temos quando entramos aqui.

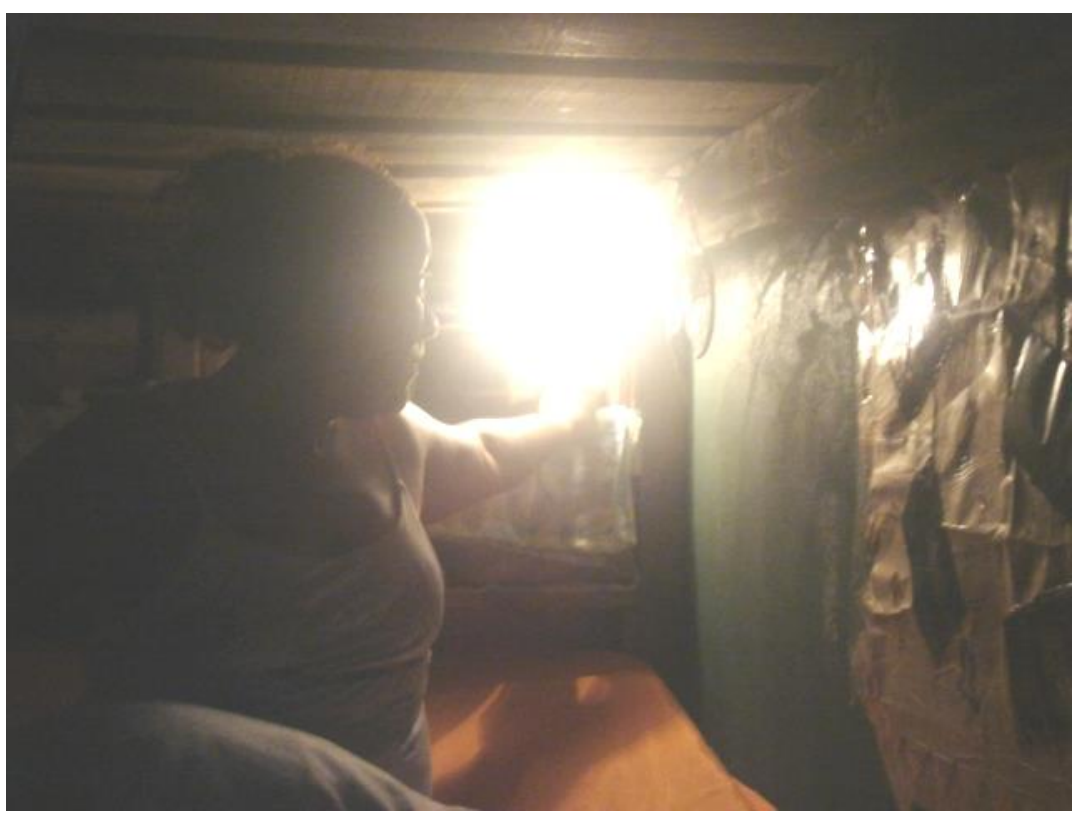

7. Cotidiano no presídio feminino: "A penumbra e o enclausuramento" Presídio Feminino de Rio do Sul/SC. Março de 2007. Autoria: Micheline Ramos de Oliveira.

Pressuponho que esse "pedido" de minha interlocutora possa ser uma pista importante para a reflexão de que a consecução de uma "obra etnográfica", por meio do 
uso de imagens fotográficas, "desafia, como no caso das etnografias mais convencionais, com base na tecnologia da escrita, o autor e o leitor a atingirem [...] o plano da "intratemporalidade" na qual se tece o caráter documental da experiência/existência humana narrada" (Eckert; Rocha, 2001: 12).

O que fica evidente na penumbra, que revela o que a própria luz encobre, como o tema do enclausuramento, do encarceramento, da ausência de liberdade, permite às minhas interlocutoras demonstrarem, através das próprias imagens, sua vivências de violências. No jogo da contra-luz, há uma escolha estética em que o tema da identidadeidem e da identidade-alter se faz presente, e com ela a manipulação da imagem de si, numa narrativa que retoma a integridade daquele que se faz presente na imagem fotográfica e que se deixa fotografar.

Enfim, espero ter atingido o objetivo desse artigo que exercitou uma etnografia da etnografia, com o intuito do rompimento dos "agoras abstratos" que só dificultam, ou melhor, mascaram o entendimento da "intratemporalidade que tece o sentido das ações/vidas humanas" (Eckert; Rocha, 2001: 12), compreensão crucial num debate em que, o que está em jogo, é a decifração das experiências de trajetórias urbanas sociais demarcadas por vivências de violências e a experiência da própria antropóloga num campo delicado e complexo como o cárcere.

\section{Referências}

BACHELARD, G. A dialética da duração. São Paulo: Editora Ática, 1994.

DIÓGENES, Glória. Cartografias da cultura e da violência: gangues, galeras e o movimento Hip-Hop. São Paulo: Annablume; Fortaleza: Secretaria da Cultura e Desporto, 2001.

ECKERT, Cornelia e ROCHA, Ana Luiza Carvalho da. "Imagens do tempo nos meandros da memória : por uma etnografia da duração". In : KOURY, Mauro Guilherme Pinheiro (Org). Imagem e Memória, ensaios em Antropologia visual. Rio de Janeiro : Garamond, 2001.

ECKERT, Cornelia e ROCHA, Ana Luiza Carvalho da. "A narrativa e a captura do movimento da vida vivida". In: Iluminuras, v.5, n.9. Porto Alegre: BIEV/PPGAS/UFRGS, 2004.

RAMOS DE OLIVEIRA, Micheline. Se correr o bicho pega, se ficar o bicho come Estudo antropológico de trajetórias sociais e itnerários urbanos sob o prisma da cultura do medo entre mulheres/mães moradoras do Bairro "Matadouro", Itajaí/SC. 2002. Dissertação de mestrado - PPGAS/UFSC, Florianópolis, 2002. 
RAMOS DE OLIVEIRA, Micheline. No limiar da memória: Estudo antropológico sobre mulheres e violências na metrópole contemporânea. 2009. Tese de doutorado PPGAS/UFSC, Florianópolis, 2009.

RICOUER, Paul. La mémoire, L'Historie, L'Oubli. Paris: Seuil, 2001.

ROCHA, Ana Luiza Carvalho da. "A irracionalidade do belo e a estética urbana no Brasil”. In: BRANDÃO, Carlos Rodrigues; MESQUITA, Zilá. Territórios do cotidiano: uma introdução a novos olhares e experiências. Porto Alegre: UFRGS, 1995.

ROUANET, S. P. "O olhar iluminista". In: NOVAES, A (Org). O olhar. São Paulo: Companhia das Letras, 1998, p.125-148.

ROUCH, Jean. "Pour La Photographie" /Ed. Ciro BRUNI. Sammeron, Germs, 1983, pp 371-375. In: Actes Du 1 er Colloque international pour La photographie - Paris: Université Paris - VIII, 1982.

Recebido em: 13/10/2012

Aprovado em: 17/12/2012 